\title{
Introduction: From Performance Research to Performance Ecologies in Contemporary Thailand
}

\author{
Pornrat Damrhung (พรรัตน์ ดำรุง) \\ Department of Dramatic Arts, Faculty of Arts, Chulalongkorn University, \\ Bangkok, Thailand \\ dpornrat@gmail.com \\ Lowell Skar (โลเวล สการ์) \\ BALAC Program, Faculty of Arts, Chulalongkorn University, Bangkok, \\ Thailand \\ Lowell.S@chula.ac.th
}

This special issue of MANUSYA explores the diverse ways that performance cultures are embedded in cultural ecologies in Thailand today. This theme emerged from work done using performance research approaches in projects done around Thailand between 2017 and 2019. These projects discovered that performance lives in cultural ecosystems, both producing new knowledge, skills and performances for those involved in them, and revealing how performance cultures were locally-grounded living assemblages of creativity in diverse Thai communities. ${ }^{1}$ These results prompted arranging the first English-language

1 As we will show below, "cultural ecology" in the sense used here overlaps with, but differs from, how anthropologists use this term. For those involved in the arts and cultural activities, "ecology" is used as a metaphor, referring to exploring the holistic and interactive cultural, social and material environments which affect the cultural activities and artistic productions emerging in those environments. The linking of culture to the ecological metaphor in this way dates mostly to the early $21^{\text {st }}$ century. Two important reports use it in this way (Holden 2004; McCarthy, et al. 2004), and since then, seeing the cultural sector in ecological terms has become more common. By contrast, anthropologists often use "cultural ecology" to focus on how groups of people interact with and adapt to their natural environments, or how societies adopt subsistence strategies depending on their environment and social factors. Julian Steward (1902-1972) first systematically used "cultural ecology" to describe how human cultures interact with their environmental settings by adapting features of technology, economic organization, and even kinship or religion to permit their people to best pursue livelihoods in those environments. Leslie White (1900-1975), Gregory Bateson (1904-1980), and Marvin Harris (1927-2001) used similar ideas in their explorations of human diversity. 
conference in Thailand to focus on performance research and to further explore the ecological dimensions of its performance cultures. This international conference, "From Performance Research to Cultural Ecologies: Creating Sustainable Artistic Communities," was held at Chulalongkorn University on July 19-21, 2019, and included scholars and cultural workers who have done similar work in the Asia Pacific. It marked a shift in focus for our work from performance research to performance within cultural ecosystems. ${ }^{2}$ Showcasing the value of innovative research through the performing arts helped to show how "ecology" can usefully be applied to performance and cultural activities as a metaphor. It drew a dozen researchers from Thailand and abroad to share their work and insights on how to develop sustainable artistic communities as fragile, but resilient and durable, cultural ecologies. The conference was the initial academic meeting of Chulalongkorn University's new "Innovation in Arts and Culture Research Cluster," which began in late 2018 as the university's first research cluster in the humanities. It seeks to produce creative knowledge that translates into empowered and innovative action in our communities and the world.

The conference pointed to both a transition and an evolution in our new performing arts research agenda, which will be seen in articles of this special issue of MANUSYA. Central to this transition is the recognition that performance research in Thailand has always bound up with cultural ecosystems. The new agenda views the performance research approaches we previously developed as part of "cultural ecologies," meaning studies of the mutually dependent social and cultural environments which affect creating and showing performances. Both types of research continue to depend on transdisciplinary creative work which involves living networks of performing artists, lecturers, students, audiences, venues and cultural organizations in evolving, fruitful partnerships in the communities that sustain them. In the new research initiative, however, we implant the tools, practices and ideas of performance research into urban performance ecologies. In doing so, we seek to develop durable urban performance assemblages that generate performance opportunities for artists, students, researchers and audiences who are committed both to enriching city neighborhoods around Chulalongkorn University and to collaborating with new international partners.

2 The conference stood near the end of a three-year Thailand Research Fund project (20162019) called "Performance Research: Doing Creative Research in Contemporary Thai Performing Arts" (RTA 5980010) and near the start of a new research initiative and performance festival (2019-2021) called "Cultural Ecologies of Performance: Creativity, Research and Innovation" (761008-02AC) supported by the Chulalongkorn University Rajadapisek Endowment fund. The Thailand Research Fund (TRF) was merged into the new organization Thailand Science Research and Innovation (TSRI) in 2019. 


\section{What is Performance Research and How is it Tied to Cultural Ecologies?}

The key insight framing the articles in this special issue is that performance cultures in Thailand are embedded in cultural ecologies. This insight grew from recent work in the field of performance research, which is relatively new to Thailand. Work done on eight performance research projects using this these new approaches uncovered how performance processes were animated in specific cultural ecosystems. Our local discovery in Thailand is related to the links of performance research and ecology made elsewhere.

Broadly speaking, performance research is research that engages creative performance-related practices and processes. Since performance research projects center on performance practices, not only is performance "practice is the main method of inquiry," but the results of performance "practice... [are] submitted as evidence of a research inquiry."3 (Nelson 2013, 8-9) In this still open and evolving field, there are diverse approaches used to research performance, with no settled approach, methodology or even goals. This diversity of approaches may be seen to fall onto an evolving continuum, however, shaped by a framework of common concerns tied to distinct forms of knowledge, methods, and impacts involving performance, but they partly diverge over how practice is seen to relate to both performance and to the public. ${ }^{4}$

Most of the performance research projects we developed gave "attention to artistic practice, whether manifest renewed focus on the materiality of theatre or as the expression of creative modes of investigation." (McKenzie, et al. 2010,13 ) Our engagement with performance research began in 2016, when the Thailand Research Fund (тRF) - now folded into the new Thailand Science Research and Innovation (TSRI) - provided an opportunity for performing arts

3 Haseman elaborates on what he sees as distinctive to this approach, stating that this type of research starts with "a specific line of scholarly investigation... into performance - by means of performance" and so "conducts research into an aspect of drama, theatre or performance through performance," often without needing "to translate questions, methods, or findings from the creative to the academic in the way other approaches to research often demand." (Haseman 2007, 148). By contrast, researchers like Henk Borgdorff and Barbara Bolt argue for the need to support or articulate artistic research or performance research practice through some writing or presentation for the public to better understand the creative work done through the practice of each project (Borgdorff 2007). More recently Arlander, et al. (2018) provide refined approaches to performance research, showing its continued development.

4 On one end of the spectrum there is the view that performance research seeks to address "questions that are pertinent in the research context and in the [performing] arts world." (Borgdorff 2007, 10) On the other end of the spectrum is the view that performance research need not start with questions but with "an enthusiasm of practice," which may not focus as much on publicly recognized academic research (Haseman 2006, 100). 
and theatre practitioners in universities to do something new for Thailand. By supporting an umbrella project on the contemporary performing arts that combined research and performance, the TRF permitted us to combine creative and academic work that spanned urban and rural performance traditions, and to focus on contemporary collaborations between communities, artists and universities. The umbrella research project "Performance Research: Doing Creative Research in Contemporary Thai Performing Arts" consisted of eight individual performance research projects based in different parts of Thailand. Each of them took a different path to research with arts practitioners, aiming to use their passion and skills to develop work to help them collaborate and share better with those in the field. Most of the underlying projects explored the interface between performance as a collective creative activity involving those in Thailand with special artistic training and performance as a type of cultural activity - including artistic work - at work in diverse Thai social contexts, as something suitable for analysis by researchers not involved in that artistic work. Several research papers in this issue involve both performance as research and research on performance by engaging performance practices and processes from several perspectives.

Work on the performance research projects from 2017 to 2019 showed how they were part of distinct ecologies of performance. We noticed how the locally-grounded and interconnected performance projects were entangled in complex, interdependent cultural systems which are best understood through the metaphor of ecological thinking. This insight made it clear that performance research depended on performance ecologies. Although the interrelationships we noticed were local and distinct to different parts of Thailand, others have likewise noticed ecological aspects of the creative arts. Baz and Nicholson noted not how performance research seeks to "create diverse and dynamic research ecologies for the future" (Baz and Nicholson 2011,3) and that this type of research is also "about the engaged social- environmental production of systems and the cultural production of flexible research ecologies wherein tacit understandings, inferred practices and theoretical assumptions can be made explicit and can, in turn, be queried and contested." (Baz and Nicholson 2011, 2). In viewing performance as embedded in cultural ecologies, we follow Ann Markusen, who describes them as "as the complex interdependencies that shape the demand for and production of arts and cultural offerings." ${ }^{5}$

5 Markusen, et al. (2011) incudes here "the many networks of arts and cultural creators, producers, presenters, sponsors, participants, and supporting casts embedded in diverse communities... cultivating a view of its wholeness and interconnectedness" in the arts and culture. Gerald Raunig (2013) goes further, seeing ecologies as forms of radical inclusion, as living symbiotic intra-active assemblages which form a commons "where each singularity 
John Holden goes further, using her definition in his report on "The Ecology of Culture" in the UK to argue for a view of "culture as an ecology rather than as an economy offers a better approach, because it provides a comprehensible overview that does not privilege one type of value - financial value - over others that attach to culture." (Holden 2015, 2) He further notes how "the use of ecological metaphors, such as regeneration, symbiosis, fragility, positive and negative feedback loops, and mutual dependence creates a rich way of discussing culture. Different perspectives then emerge, helping to develop new taxonomies, new visualisations, and fresh ways of thinking about how culture operates." (Holden 2015, 2). ${ }^{6}$ The complex forms of cultural performance work by integrating themselves with other forms of locally grounded cultural life which are tied to groups at work in the same locale. This makes them dependent on their interactions with one another. By seeing performance projects as embedded in local ecologies on which they depend, the performance research projects can be understood as more than just activities centered on culture, economics, politics or social organizations. Using the metaphor and the language of ecology helps to enrich how we think about our involvement in relations to performance, both as a type of aesthetic activity and a type of knowledge and skill production. It lets us both to recognize and to act within these ecologies of performance more effectively and in a more self-aware way.

The different performance research projects we had in Thailand involved 20 university scholars and 14 local artists between 2017 and 2019 as the main researchers, performance practitioners, critics and evaluators from around Thailand. These participants helped to reflect, refine, and interact with the eight projects as they evolved. The diverse types of production and research results have helped expand and connect contemporary audience-based performances in cities with those found in community-based performances and local festivals. They also generated new interactive spaces and created new

can live out its own strangeness to the extent of its possibilities, and experiment with its own form of concatenation."

6 Holden $(2015,2-4)$ links culture to the "ecology" metaphor in several ways. First, culture appears "in concatenations, 'flowerings', events and assemblages" of many different types of elements, actors, practices, and processes. Second, it is part of "a regenerative life cycle" or a rhythm of interactive activity which ebbs and flows, rises and falls in patterned ways. Thirdly, ecology encompasses a complex dynamics of movement and time - from the slow to the sudden, which work at different scales, including traditions, innovations, hybrid mixes, new trends, and fads, etc. Fourthly, it consists of "of linked phenomena... [depending on] connections.... The cultural ecology does not only consist only of human actors. It should be seen as including inanimate objects like concert halls and movie cameras that can be considered as 'actors' in their own right. Culture happens when people, with their ideas, skills and abilities, find the right opportunities. In turn, opportunities are enabled by things: money, equipment, streets, buildings, objects." 
performance networks which remain as interactive creative spaces to this day. They are key products of performance research. Not only were they part of cultural ecosystems, but they also helped to foster new ecosystems. That creative potential is also a hallmark of our new research agenda. Seeing that performance cultures are entangled in cultural ecologies does not mean that researchers always focus on both equally. Most of the projects considered in this issue focus on how different performance practices in Thailand are or can be considered as contemporary work. But the projects are also forms of artistic research. Several performance research projects emerged from artists and theatre practitioners based in universities in Thai provinces who wanted to work in their own communities and to seek how to re-create a contemporary work rooted in traditional knowledge in their communities and to perform the work in their local community festivals. Other five projects arose from artists and theatre practitioners based in Bangkok universities, and sought to reinterpret traditional stories and to recreate them in ways to find new meanings that would be more relevant to contemporary audiences.

The performance research projects rose from the passions of the artists and arts practitioners and unfolded through the practices the teams used to collectively realize their visions. Their projects began from different starting points, working atmospheres, rehearsal processes, and performance cultures that gave new experiences and perceptions to audiences. Some artists and researchers may have wanted to tell old stories differently, while others sought to retell them from new perspectives or using new techniques. They all aimed to produce new concepts or practices they could share with their audiences. ${ }^{7}$ The articles included in this special issue all engage the insight that performance research is embedded in cultural ecologies, but each article expresses that engagement differently.

\section{Contributions to this Special Issue}

This issue of MANUSYA is based on the premise that performance research and cultural ecologies are deeply interconnected phenomena. Its contributions address both performance research and cultural ecologies, but they vary in which one is given most emphasis. For that reason, the special issue will fall into two main parts, the first part for the articles which focus more on performance

7 Their performance-based projects produced results that are normally identified as research in academic settings - documentation, dissemination, and utility through being transferable. Besides the various performances onstage done around the country and sometimes abroad that rose from the eight projects, two books were published from these TRF projects in 2019. See Damrhung, et al., 2019a and 2019b. 
research and the second part for those which focus more on performance in cultural ecologies. ${ }^{8}$ The issue will be framed by the keynote speaker's contribution and the summary of three roundtable sessions held throughout the conference. Danny Butt, the conference keynote speaker, provides an overview of artistic research in the Asia Pacific. Articles which focus more on performance research include those by Sinnapa Sarasas, Dangkamon Na-Pombejra, Phakamas Jirajarupat, and Nataporn Rattanachaiwong, Piyawat Thamkulangkool. Papers giving more attention to cultural ecologies include those by Pornrat Damrhung, Lawrence Ross, Khalid Midam, Lowell Skar, and Pachaya Akkraphram. A final paper in the issue analyzes an improvisational piece of creative research done and three Roundtable sessions held during the July 2019 conference. $^{9}$

Danny Butt from Victorian College of the Arts at the University of Melbourne opened the conference by providing insights on how artistic research in the Asia Pacific could provide a critical voice for artistic inquiry. His long experience of putting artistic research to work in a changing environment raised key important questions to open the conference. The paper printed in this issue builds on his important 2017 book and suggests that innovation and experimentation with local artistic forms is one way for artistic research to enliven the 21st century university mission in the Asia Pacific. (Butt 2017) University artistic research programs "have the opportunity to foster new forms of collaboration in artistic research that can keep the spirit of regional collaboration alive."

To better understand how these types of collaborative artistic research work in specific cultural ecologies in Thailand, Part One of the issue focuses on the design and processes of intercultural and innovative performance projects. The projects discussed here focus more on performance research tied to local areas in Thailand, while allowing Thai and contemporary artists and audiences to interact with one another, and create unique interdependences and synergies. The works differed give local Thai artists leading or new roles in these innovative projects. They sought to enrich their work with modern modes and structures to support plots or as forms to produce performances that were relevant for contemporary audiences. Despite their focus on the creative process, these research projects were embedded in distinct cultural ecosystems.

8 This is elaborated in Damrhung, et al. 2019a \& 2019b and in Damrhung 2020.

9 The articles of the special topics publication discussed here will be printed in two consecutive issues of MANUSYA. Most articles will appear in this issue 23.3, but the articles by Sarasas, Midam and Thamkulangkool will appear in 24.1 of MANUSYA. Photographs and other visual materials tied to the articles in this special issue will be available online at the URL https://doi.org/10.6o84/mg.figshare.13265333 
Khru Thammanit Nikomrat, from Thaksin University in Songkhla, and Sinnapa Sarasas, at Silpakorn University, collaborated on a new musical overture to celebrate the ceremony for the goddess Lim Gor Niew at her large and famous shrine in Pattani province in 2017. Seeking to combine music from artists of three distinct musical traditions and faiths in Southern Thailand, their collaboration showed the harmony of working on music together, merging the communities with music and arts. Sinnapa's paper provides insight into her working process in the overture that allowed the artists to work independently and as part of a cooperative ensemble through a type of conservative creative musical innovation. ${ }^{10}$

By contrast, Dangkamon Na-pombejra from Chulalongkorn University sought to revitalize the critical potential of the familiar Thai version of the The Merchant of Venice studied in schools by reworking it into a tool for altering how people relate to "the other." In directing his version of this play in his university in 2018 , he stressed how focusing on a theme and using alienation effects, he could change what Thai audiences were familiar with, and alter their view of the play and their attitudes toward those different from themselves. Audiences were presented with direct experiences of unfamiliar things and their own prejudice against others and asked to re-consider themselves and how they relate to others.

Another way to enliven the old was done by the makers of Leh Laweng (The Wiles of Laweng) in 2019. By creating a new play in a "post-traditional" style of the Lakhorn Phanthang or contemporary hybrid theater form, Phakamas Jirajarupat and Nataporn Rattanachaiwong from Suan Sunandha Rajabhat University give a new woman-centered interpretation to the play, breaking from standard versions derived from the romantic Thai epic poem Phra Aphai Mani done by the renowned poet Sunthorn Phu. The story was loved and re-told in text and dance drama form often staged in the Lakhon Panthang form, but the authors devised a new script and performance from the point of view of a relatively minor character, a foreign warrior queen from the west. The performance adapted and was directed in what the authors call a "post-traditional" hybrid theatre style and asked performers to move and interact onstage in unfamiliar ways, thus helping to reach contemporary audiences.

Piyawat Thamkulangkool's article turns the focus of performance culture toward the challenges of developing audiences. He examines the relations between audiences in Thailand who attend non-mainstream contemporary theatre and dance and the groups which produce these pieces to determine the barriers to building audiences for this type of performance. He stresses how the audience development process requires focusing on both performance-

This article will appear in the next issue, 24.1, of MANUSYA in March 2021. 
making and organization and management, since only through the cooperation of all stakeholders will this performance culture develop sustainably into ecologies. His paper forms a good bridge into Part Two of the issue, dealing with performance ecologies in Thailand crucial for future developments. ${ }^{11}$

The shift to focusing on cultural ecosystems of performance led to a new focus in our research, too, in the new "Cultural Ecologies of Performance: Creativity, Research and Innovation" project, which received support from Chulalongkorn University, as part of a broader research cluster on the arts and culture begun in late 2018 .

In focusing on the cultural ecosystem where performances take shape, Part Two of the issue stresses the current and future work of the new research cluster that began in late 2018 at Chulalongkorn University. Pornrat Damrhung from Chulalongkorn University writes about the distinct working process that Saran Suwannachot - Khru Nick - used to develop the piece "Pu Nang, the Great Ancestor" in 2017 in Chiang Mai. This new form of traditional dance theatre emerged from the teaching of diverse local arts at the Lanna Wisdom School. This local reproduction of local knowledge and practice in the arts consists of a distinct cultural ecology that is unique to the school, but which could be seen in other performance processes, too. By elaborating on the working process Khru Nick used to tell the story in a different platform that would allow his traditional colleagues and students try a different work environment to show how to retain their cultural ecology today. It sought to develop an alternative way to adjust their wisdom in the arts school into contemporary life, and provided a path to understanding the workings of Thailand's distinctive cultural ecology in the arts.

Looking into the cultural ecosystem of the "Rong Ngeng" form of music and dance in the Andaman Sea coastal region of Southern Thailand, Lawrence Ross, from the University of Malaya, gives an ethnohistory of Rong Ngeng performance culture in recent decades as a transnational cultural form spanning the Malaysian and Thai borderlands.

Khalid Midam, from Burapha University in Bangsaen, created his Bar'zanyee piece to retell miracles of the Prophet Mohammed based on the famous poem Al-Burdah (The Poem of the Scarf) by Șālih Sharaf ad-Dīn Abū 'Abd Allāh Muhammad ibn Hasan Al-Būșīn̄ (1212-1296), which praised the Prophet Muhammad (Peace Be Upon Him) for healing its author. Using six Pondok students from Bangkok who trained in the Barzan'yee singing style, he used developed a performance to connect the young singer's chants of the poem to events in the performers' own lives. This would help both Muslim and non-Muslim 
audiences to understand new aspects of Muslim identity and Muslim culture in Thailand. ${ }^{2}$

Lowell Skar from Chulalongkorn University develops a framework for exploring some contemporary performance groups in Bangkok using a cultural ecology approach rooted in dimensions of "play" found in practice theory and performance studies. Doing so can help to situate the work of these groups in distinct but overlapping performance ecologies across the contemporary Thai performance landscape.

Pachaya Akkapram's article looks at the diverse impacts of the puppet theatre project he led at Khon Kaen University in a unique and the ongoing performance ecology he helped to create there. By involving six university students in learning Isan culture from the ground up with local artists and villagers in a community in northeastern Thailand, the students made original puppets, devised a script of some episodes of Sinxai accompanied by morlum singing and created a performance. They immersed themselves in their own local culture and created a musical puppet performance. The project has been performed more than 40 times around Thailand and abroad, helping to give confidence to the participating students and the researcher, to support further creative interactions between the university and local artists and villages, and to see new ways to use applied theatre to interact with communities.

A final summary of three roundtable sessions of the July 2019 conference shows how creative ecologies work in practice in both their creative and their academic modes. It examines, in live and interactive settings, how performance research is related to the artistic research and to cultural ecologies of diverse communities. Importantly, the roundtable included a short new collaborative work-in-progress done by artist-researchers on July 19. Their experimental piece, "Catching the Swan 2019" ("Klong Hong 2019") involved the creative interaction of two dancers, master Thammanit Nikomrat and master Saran Suwanachote from Chiang Mai, who were accompanied by musicians Sinnapa Sarasas, Sa-Ngiam Lertjiraratong, and Torpong Samerjai in a live improvisational performance based on a well-known legend. Charlene Rajendran from Nanyang Technological University in Singapore and Lawrence Ross led the July 19 roundtable. The short performance and earlier presentations led to artists, practitioners, researchers, students and the audience to reflect on the conference in a roundtable that would later lead to discussion of cultural ecologies issue on the second day, when Charlene expertly led the July 20 roundtable session on her own, helping to pose intriguing questions and to draw out important insights and perspectives from various participants.

12 This article will appear in the next issue, 24.1, of MANUSYA in March 2021. 
Moderators did excellent jobs, as seen through the roundtable summaries in this special issue. Since research in the arts and culture tied to practice and performance is a new path for us, we wanted to see if we could explore them with other scholars and artists from the region. A final short roundtable session on July 21 sought to develop loose connections for a new platform for artistic research and cultural ecology for those in the arts and research practitioners in Asia-Pacific.

Other scholars doing artistic research and artistic practice also gave public presentations in July, dealing with their own research in the arts grounded in local cultural ecologies. Our invitations brought in four scholars from other universities to share their views about performance practice and their concept of cultural ecologies. To show the international dimension of artistic research and how they can be used to understand performance in relation to cultural ecologies, several other articles from the conference round out the special issue. Previous commitments and busy schedules prevented Mark Teh, an Artist-Producer-Educator based in the Five Arts Center in Kuala Lumpur, Malaysia and Jeungsook Yoo, an actor-director scholar who teaches in the Korea National University of Arts and Soongsil University (Korea) from including their presentations to this issue. ${ }^{13}$

The July 2019 international conference "From Performance Research to Cultural Ecologies: Creating Sustainable Artistic Communities" provided the source for the presentations this special issue of MANUSYA. The special issue includes diverse creative scholars, artists and researchers from the Asia-Pacific. After presenting their articles and receiving feedback from those in attendance, the authors reintroduced themselves and their work to one another and allowed new friendships to form. They then revised their articles into submissions for the journal. By joining together to consider how performance and artistic research feeds into performance ecologies, we seek in this special issue of MANUSYA to help cultivate new ways of thinking and working and new relationships to sustain both how we imagine and practice performance in our communities and how we can continue our work with one another.

\footnotetext{
13 Mark Teh was the second keynote speaker for the conference on July 20, reflecting on his work in "Playing with Dust: Reflections on Performing \& Researching," by discussing how he used interdisciplinary and transnational creative practice to produce multidimensional situated knowledge by exploring several long-term projects he has been involved in. Jeungsook Yoo presented on "A Korean Approach to Acting with Meditation: The notion of $k i$ and Dahnhak meditation training" on July 20 and led a workshop for students using this method on the morning of July 21. See photo of Mark Teh and Jeungsook Yoo at URL https://doi.org/10.6o84/mg.figshare.13265333.
} 
This special issue helps to show how we moved from our previous work in performance research to our current work in cultural ecologies of performance. Each represents a new direction for creative research in the performing arts in Thailand. They both point toward new ways to relate performance and theater to forms of life that are at work in different communities and cultural ecologies around Thailand. The transition of our focus from performance research to performance in cultural ecologies of performance represented by the articles of this special issue of MANUSYA show a move of our work toward the diverse ways that performance is rooted in the cultural ecologies in Bangkok's diverse communities.

\section{3}

\section{Concluding Remarks}

This special issue of MANUSYA helps to mark the beginning of a new Arts and Culture Research Cluster at Chulalongkorn University. In considering how performance cultures are part of cultural ecologies, it is one of many research, educational, and innovative initiatives that form a larger trend-a veritable "creative turn"-in the 21st century global research priorities of higher education. This trend identifies creativity in general and in culture - and artistic production in particular - as key catalysts and enablers of economic, political, social, and scientific innovation and development. The original research in art and culture of this cluster aimed to generate tangible benefits for the creative and cultural life of not just the university, but for society in Thailand and beyond. The July 2019 conference received funding from the International Research Forum in the Ratchadaphiseksomphot Endowment Fund, which seeks to be a catalyst for new international academic links which enable personal and scholarly contacts to develop and grow into durable networks and institutional partnerships able to produce innovative artistic and cultural scholarship, teaching, and creative practice.

The part of the new research cluster umbrella organizing this conference is called "Cultural Ecologies of Performance: Creativity, Research and Innovation" begun in late 2018. It shows our university's commitment to enhancing the roles of the arts in university life, new ways of engaging the arts for society. It highlights the unique power of the performing arts to reach and move the larger public and to engage the wider world. Funding for seven distinct creative projects based in four of our faculties - Arts, Fine Arts, Communication Arts and Education - sought to produce interdisciplinary and collective work that aimed to form the core of an international performing arts festival scheduled for March 2020, but this was largely delayed or postponed due to the CoviD 19 
pandemic. ${ }^{14}$ Preparation for the distributed festival involved the joint efforts of senior artists and scholars with several new lecturers and a half dozen postgraduate students and more than twenty undergraduates from four faculties at Chulalongkorn University. The training and experience they gain in this process will lay the foundation for their future involvement in creative collaboration, both in Thailand and abroad. The beneficial interdisciplinary approaches they undertake will spur creative connections and meaningful innovations.

The new humanities research cluster and this special issue of MANUSYA contributes to the goals of the cluster and to Chulalongkorn University's mission as a research university tied to local communities and the connected to the larger world. To help make the performing arts better known in academia, some of the results of this conference will be published in an academic journal. Young researchers will learn to work in the field, to develop new skills for creative challenges, and to publish their findings for the wider performing arts community. This work prepares participants to confront challenges with greater expertise and creative confidence.

The conference included universities - students, faculty, and leaders - and creative people from across the Asia-Pacific who seek to engage and integrate the arts and culture into the pursuit of basic knowledge and everyday practice. ${ }^{15}$ As a $21^{\text {st }}$ century research university, Chulalongkorn values the arts and culture as central parts of both research and higher education, whether for developing transdisciplinary knowledge and applied research in the arts, or for interdisciplinary creativity, durable collaboration, and diverse communities, all of which can become key tools for building a better world.

The 2019 conference helped consolidate the understanding of artistic research in the performing arts in Thailand and to connect its efforts with similar efforts elsewhere in the Asia-Pacific. Some of these results appear in this the articles of this journal. Others appear in the performance-related projects developed in 2019 and 2020. Most importantly, it sought to develop a framework to stress how the performing arts are always embedded in living communities and concerns beyond the stage - what we have called here "cultural ecologies." Although we had planned to show how performance was tied to cultural ecologies in our festival distributed through 2020, many of these projects have had to

14 Due to the covid-19 outbreak, the scope, timing and character of the planned festival needed to change. Some parts were held in late 2019 and earlier in 2020 and some parts will be held later in 2020.

15 Pornrat Damrhung and Khalid Midam followed up this conference by attending the first meeting of the Asia Pacific Artistic Research Network (APARN) in October 2019. It was co-organized by the Centre of Visual Art in Melbourne by another conference attendee, Dr. Danny Butt, and researchers at the Indonesian Institute of the Arts Yogyakarta. 
be postponed or presented in a modified way due to the CoviD 19 pandemic. The others will appear in new settings during the coming months. Our performance work in cultural ecologies will also appear in future connections that its researchers are developing in their work rooted in local communities and expanding through global connections. Those involved in the performing arts regularly use interdisciplinary approaches in our performance research work. By locating our performance work in more complex settings and connecting it to forms of knowledge and expertise rooted in cultural ecologies beyond the stage, our research is also developing transdisciplinary approaches which seek to ensure support for research, curricula, programs and creative practice that involve performing arts to develop solutions to complex problems connecting the arts, sciences, and other disciplines. We hope to develop high-quality scholarly and creative activities when disciplines are free to experiment in and across their boundaries. This work can support efforts to demonstrate the performing arts are crucial to developing new fields of research, and playing key role in Thailand's cultural and economic development, and fostering competencies in creativity, innovation, and communication that are essential to the future of our world.

Central to this goal was the plan to hold an extended festival centered on the theme of "performance for life" that spanned late 2019 and 2020 and called Life | Performance. This new type of distributed festival aimed to strengthen and advance the arts and culture in research, teaching, scholarship, creative practice, and innovative events and organizations in our society by using performance practices in the diverse cultural ecologies of urban communities around Chulalongkorn University. The diverse projects sought to use drama techniques and concepts in the lives of those who did not know much about theatre, to involve non-theater people in performance-based practices and ideas in order to expand the social uses and value of performance beyond ordinary theatre spaces. In line with these goals, the main venues planned for the various components of the festival were to be offstage and outside theater spaces, in various urban spaces around the university. Although some of the projects of the festival from late 2019 were held as planned in and around Chulalongkorn University, the covid 19 pandemic forced a radical rethink and restructuring and further extensions of the festival format in 2020. ${ }^{16}$ With the

16 The Performance Practice as Research (PPAR) initiative organized and ran the Life | Performance urban performance festival from the Department of Dramatic Arts at Chulalongkorn University. On Facebook it is found @ThaiPerformancePracticeResearch/. It included several talks, workshops and performances in late 2019 and into 2020, including those tied to Likay (Sep. 28-29), Nora (Oct. 26-27), Chinese opera (Nov. 2), Eko Suprinyato's "Urban Ecology - Dance Lab" and work-in-progress (Nov. 23-25) - all in the "From 
university moving to shut down from late February 2020 and fully closing from mid-March, and with all performance spaces in Bangkok likewise closed under the city's March lockdown, many of the performance projects for the festival were reworked into online settings, while others were postponed to times when the university was expected to open up. ${ }^{17}$ The COVID outbreak also led to the development of new online formats for the research done in this cluster.

The participants and guests to the July 2019 conference contributed to the research agenda outlined above and appear in this special issue of MANUSYA, whether from Thailand or the wider Asia-Pacific region. We seek to further develop more connections, insights and ideas which will develop into future relationships, collaborations and activities in the wake of the COVID 19 pandemic. We hope to help universities - students, faculty, and leaders-to acknowledge, embed, and integrate the performing arts into their local communities and by doing so, to develop new knowledge and to link to everyday practice. By promoting the role of the arts and culture in research universities, which focus on research and synthesis, and to link them to the cultural ecologies they are part of, we seek to develop transdisciplinary forms of connected knowledge and to empower leadership to help advance the performing arts and culture in research, teaching, scholarship, and creative practice. We hope to enable institutional support for arts-integrative research, curricula, programs and

Experts to Offspring" section of the festival. While the workshop events were limited, the public events had 150-400 attending. Online social media engagement with these events included thousands of visits shares, and views to FB posts and videos. The Festival also included the new "Bu Lan Cha La" Likay performance at the Rong Meung Reung Yim Festival by Hua Lamphong on December 1 . The final work in this festival before the Covid 19 lockdown of Bangkok done by the Japanese group Gecko Parade, who did workshop at Chulalongkorn University Museum on Sep. 13-14, 2019 on "Lindbergh's Flight: a TransArchitectural Journey" and performed it on March 12-14 in the Slure Project and café near the Thaksin BTS station, with support from the Japan Foundation Bangkok.

17 While under the lockdown, since May 2020 PPAR has developed and posted a series of podcasts on Thai Performance Practice as Research as new outreach efforts for the Life | Performance urban performance festival, in what is called "Art in Time of Social Distancing." Each of the three podcasts on Thai Performance Practice as Research forum posted in May has been listened to by about 500 visitors as of early June. There is also a collaborative project "Folklore, Music and Performance: Thai-Khasi Explorations" done by Chulalongkorn Department of Dramatic Arts graduate students and faculty and students from the North-Eastern Hill University in Shillong, India. The first public event for the extended urban festival after the partial re-opening will be at Chulalongkorn University on July 3-4, 2020, when Pichet Klunchun will hold his No.6o: Exhibition | Demonstration at the Chulalongkorn University Museum and release of his new book No.6o, based on this research. Between July and September 2020 there will be several online talk sessions of "Arts as Therapy, Arts as Tools, and Arts for Living" before a September 2020 conference showcases the results of research projects done by those involved in it. 
creative practice between the arts, sciences, and other disciplines. We seek to support the growing areas of high-quality scholarly and creative production which emerges when disciplines are free to experiment within and across their boundaries. We hope to develop ways to show how the arts are crucial to developing new fields of research, to playing key roles in Thailand's cultural and economic development, and to nurture competencies in creativity, innovation, and communication that are crucial to the future of our world.

\section{Acknowledgements}

We wish to offer special thanks to Professor Dr. Amara Prasithrathsint for considering the topic and the articles for this special issue of V:Journal of Humanities and to Ms, Chantharas Kanchanakool, who patiently and carefully worked us through the editorial process. Two anonymous reviewers of an earlier version of this article provided many thoughtful and practical suggestions which the authors have sought to include in this revised version. We thank them both for their careful reading of the manuscript which has improved the result.

\section{References}

Arlander, Annette, Bruce Barton, Melanie Dreyer-Lude, Ben Spatz, eds. 2018. Performance as Research: Knowledge, Methods, Impact. New York: Routledge.

Borgdorff, Henk. 2007. "The Debate on Research in the Arts." Dutch Journal of Music Theory 12 (1): 1-17.

Butt, Danny. 2017. Artistic Research in the Future Academy. Chicago: Intellect/University of Chicago Press.

Damrhung, Pornrat, et al. 2019. "Kham sat kham wela: wicai kan sadaeng nai withi niwet watthanatham" (Cross-Disciplines, Cross-Times: Performance Research in a Cultural Ecology Approach). Supported by the Thailand Research Fund (TRF) / Thailand Science Research and Innovation (TSRI). Nontaburi: Parbpim Publisher.

Damrhung, Pornrat, et al. 2019. "Prakotkan kan sadaeng: mahawitthayalai nai withi niwet watthanatham" (Performance Phenomenologies: University in a Cultural Ecology Approach). Supported by the Thailand Research Fund (TRF) / Thailand Science Research and Innovation (TSRI). Nontaburi: Parbpim Publisher.

Damrhung, Pornrat. 2020. "Refreshing the Spirit of Creativity: The Cultural Ecosystem Approach at the Lanna Wisdom School, Chiangmai." In Spirit of Creativity in Dance Education. Edited by Mohd Anis MD Nor. Kuala Lumpur: Nunsantara Performing Arts Research Center. 
Haseman, Bradley C. 2006. "Manifesto for Performative Research" Media International Australia Incorporating Culture and Policy Journal of Media Research and Resources 118: 98-106.

Haseman, Bradley C. 2007. "Rupture and Recognition: Identifying the Performance Research Paradigm." In Practice as Research in the Arts: Approaches of Creative Arts Inquiry. Edited by Estelle Barrett and Barbara Bolt, 147-57. London: I. B. Tauris.

Holden, John. 2004. Capturing Cultural Value: How culture has become a tool of government policy. London: Demos.

Holden, John. 2015. "The Ecology of Culture: A Report commissioned by the Arts and Humanities Research Council's Cultural Value Project." London: AH RC.

Kershaw, Baz, and Helen Nicholson, eds. 2011. Research Methods in Theatre and Performance (Research Methods for the Arts and the Humanities). Edinburgh: Edinburgh University Press.

Markusen, Ann, Anne Gadwa, Elisa Barbour, and William Beyers. 2011. California's Arts and Cultural Ecology. San Francisco: James Irvine Foundation.

McCarthy, Kevin F., Elizabeth H. Ondaatje, Laura Zakaras, and Arthur Brooks. 2004. Gifts of the Muse: Reframing the Debate about the Benefits of the Arts. Santa Monica, CA: The Rand Corporation.

McKenzie, Jon, Heike Roms, and W-L C. J. Wee, eds. 2010. Contesting Performance Global Sites of Research. New York: Palgrave Macmillan.

Nelson, Robin. 2013. Practice as Research in the Arts: Principles, Protocols, Pedagogies, Resistances. New York: Palgrave Macmillan.

Raunig, Gerald. 2013. "n-1. Making Multiplicity. A Philosophical Manifesto." European Institute for Progressive Cultural Policies. Accessed September 15, 2019. Retrieved from: https://transversal.at/transversal/1011/raunig2/en. 